\section{Factors Influencing Water Split of Pecan Fruit}

\author{
Bruce W. Wood and Charles C. Reilly \\ U.S. Department of Agriculture, Agricultural Research Service, Southeastern \\ Fruit and Tree Nut Research Laboratory, Byron, GA 31008
}

Additional index words. nuts, damage, rain, crop loss, humidity, production, Carya illinoinensis

\begin{abstract}
Water stage fruit split (WS) is an erratic and complex problem often causing major crop losses to susceptible pecan [Carya illinoinensis (Wangenh.) K. Koch] cultivars. This study identified two episodes of WS for 'Wichita' pecan-a highly susceptible cultivar. The previously recognized precipitation-induced fruit splitting is the major episode; however, a previously unrecognized precipitation-independent, minor episode can also occured before the major episode. This minor episode was associated with the low solar irradiance and high relative humidity-conditions commonly associated with August rains. The crop characteristics of affected trees also influenced WS in that WS increased as crop load per tree increased. Fruits were also more likely to exhibit WS if located within the lower tree canopy. Treatment of foliage with an antitranspirant immediately before split-inducing conditions increased WS. Maintenance of moist soils for $\approx 2$ weeks before WS-inducing conditions substantially reduced WS-related crop losses. These findings help to explain the erratic nature of WS and indicate that maintenance of trees in a well-watered state for $\approx 2$ weeks before the initiation of shell hardening may substantially reduce WS-related crop losses in certain years.
\end{abstract}

Pecan exhibits a fruit splitting problem where the ovary wall (shell), underlying testa (seed coat), and usually the involucre (shuck) splits about the time of shell hardening. This "water stage fruit split" (WS) often causes severe crop losses in susceptible cultivars (Storey, 1969; Worley and Taylor, 1972). Similar splitting of the flesh or skin of certain other fruit crops [e.g., apple (Malus domestica Borkh.) (Goode et al., 1975), cherry (Prunus avium L.) (Verner and Blodgett, 1931), and plum (Prunus domestica L.) (Mrozek and Burkhardt, 1973)] also causes major economic losses, but the ovary wall of these fruit does not split as it does in pecan.

A dearth of information on the factors contributing to WS has largely precluded the application of cultural practices that adequately protect against crop losses. Water split is highly erratic, with occurrence and severity varying with cultivar, location and year (Prussia et al., 1985). It is most commonly exhibited by thinshelled cultivars, such as 'Schley', 'Wichita', 'Sumner', 'Farley', and 'Frotscher', but can also occur in relatively thick-shelled cultivars, i.e., 'Cape Fear' and 'Elliott'. Developing fruits are briefly vulnerable just before the initiation of kernel filling ("late water stage") a time when turgor pressure is high in the liquid endosperm (Prussia et al., 1985) and the shell is becoming rigid (Allison et al., 1987). In the Northern Hemisphere, this is typically during mid-August for most cultivars. At this time the cotyledon expands rapidly within the ovule and compresses the internal packing tissues just before the beginning of kernel

\footnotetext{
Received for publication 28 Apr. 1998. Accepted for publication 4 Dec. 1998. The cost of publishing this paper was defrayed in part by the payment of page charges. Under postal regulations, this paper therefore must be hereby marked advertisement solely to indicate this fact.
}

HortSCIENCE, Vol. 34(2), April 1999
The relationship of WS to the general location of fruit within the canopy was estimated by monitoring the percentage of WS fruit occurring in the upper and lower of the canopy of heavily fruiting trees. Percentage of WS was based on sampling of 50 clusters, each consisting of four fruit. The experimental design was a randomized complete block (RCB) with four blocks ( $\mathrm{n}=8$ trees per study). Treatments were two canopy locations (upper third vs. lower third). Statistical analyses were by ANOVA.

Expt. 2. WS as related to soil moisture. The relationship of WS to soil moisture several days before, and up to, split-inducing conditions. This consisted of two soil moisture regimes: a) moist ( $\geq 8 \%$ water), where sprinklers applied water from $\approx 2$ weeks prior (late July) to normal occurrence of split (near midAugust) to the end of split susceptibility (late August), and b) dry ( $\approx 2 \%$ to $3 \%$ water), with only rainfall. Soil moisture was monitored gravimetrically before the occurrence of WSinducing rainfall. The RCB design included six trees for each of the two treatments $(n=12$ trees). Trees were blocked according to crop load. Percentage WS was monitored on fruit clusters possessing four or more fruit. Fruit clusters were randomly selected from the lower third of the canopy. Irrigated trees received $\approx 275 \mathrm{~L}$ of water per tree every other day, which is the recommended level for similar sized trees in Georgia (Daniell, 1989). The 3week period before splitting was generally dry, but with an occasional light thundershower. Percentage of split per 50-100 fruit clusters per tree was analyzed via ANOVA. Soil water content in the upper $18 \mathrm{~cm}$ of the profile was determined gravimetrically by drying samples at $110^{\circ} \mathrm{C}$. While prolonged exposure of trees to low water availability can reduce fruit size, a sampling of fruit from each treatment at the time of WS indicated that irrigation during the $\approx 2$ weeks of the study did not significantly $(\alpha<0.15)$ influence fruit $(6.1$ $\mathrm{cm})$ or cotyledon $(4.7 \mathrm{~cm})$ length. Thus the two moisture treatments produced fruit of essentially equal size.

Expt. 3. WS as influenced by an antitranspirant. The influence of a foliar antitranspirant on WS was evaluated by comparing two treatments: 1) antitranspirant sprayed onto the foliage of the entire tree the day before the occurrence of a split-inducing rainstorm, and 2) untreated control. The antitranspirant [Wilt-Pruf (1:10 v/v mix with water; Wilt-Pruf Products, Essex, Conn.)] was sprayed onto both upper and lower surfaces of foliage until run-off. This study used eight moderate to heavily cropping trees (blocked by crop load) managed without supplemental irrigation. The RCB design contained four blocks of two antitranspirant treatments. Percentage WS was measured $2 \mathrm{~d}$ after the splitinducing rainfall on 50 clusters having three or more fruit and located within the lower half of the canopy.

Expt. 4. Association of WS with weather conditions. The relationship of WS to relative humidity, solar irradiance, and rainfall was assessed on four trees with heavy crops. Be- 
cause of alternate bearing, these individual trees differed in crop load from year to year. A recording hygrothermograph continuously tracked orchard relative humidity from 5-15 Aug. - the period in which WS was expected to occur. An adjacent weather station provided daily monitoring of rainfall and solar irradiance. In Aug. 1995-97, WS was recorded as related to these environmental factors. Trees were monitored for splitting fruit almost daily from 5 to 15 Aug. during early morning (6:308:30 AM) and again in mid-afternoon (3:00 $4: 30 \mathrm{PM}$ ) by randomly inspecting a total of $\approx 50$ fruit clusters (on the lower third of the canopy but independent of cluster size) per tree. Observations were also made at night (ranging from 10:00 PM to 5:00 AM) upon first detection of WS fruit.

\section{Results}

Expt. 1. WS as related to crop load and canopy location. As the average number of fruit per shoot increased WS increased curvilinearly (Fig. 1). There was $\approx 9$-fold difference in WS as crop load increased from very low to very high. The location of fruit within the canopy also influenced the percentage of WS fruit. Only $5 \%(P \leq 0.05)$ of the fruit from clusters within the lower third of the canopy split vs. $14 \%$ of those within the upper third. Most fruit dropped from the tree 6-7 d after splitting, although a small percentage of them remained attached to the tree.

Expt. 2. WS as related to soil moisture. The 1995 crop season was abnormally dry, and 'Wichita' trees did not exhibit WS (Fig. 2A). In both 1996 and 1997 seasons, substantial WS was evident, less than $24 \mathrm{~h}$ after thundershowers deposited $\approx 4.5$ and $1.5 \mathrm{~cm}$ of water, respectively, onto the orchard floor. Trees growing on both relatively moist $\geq 8 \%$ water) and dry ( $\approx 2 \%$ to $3 \%$ water) soils exhibited WS, but percentage WS was $\approx 3$-fold greater in trees growing on the drier soil (12\% vs. $33 \%$, respectively, differences significant at $P \leq$ $0.05)$.

Expt.3. WSas influenced byantitranspirant. The percentage of WS in trees receiving an antitranspirant $\approx 1 \mathrm{~d}$ before split-inducing rainfall was $20 \%$ vs. $14 \%(P \leq 0.05)$ in untreated trees; thus the antitranspirant increased WS $43 \%$. Measurements of stomatal conductance of treated foliage verified that gas exchange was diminished by the antitranspirant.

Expt. 4. Association of WS with weather conditions. Weather during the WS susceptibility window in 1995 was very dry, with essentially no precipitation during early shell hardening. Solar irradiance was also higher during the critical period than in subsequent years (Fig. 2A). In 1996 and 1997 there were two WS episodes (Fig. 2 B and C), a minor one followed by a major one. The frequency of WS in the minor episode ranged from $\approx 1 \%$ to $3 \%$ (depending on year), whereas the major episode affected from $\approx 18 \%$ to $27 \%$ of the fruit within the lower third of the canopy. The minor episode preceded by $1-2 \mathrm{~d}$ rainfall (only a single rain within 7-11 d) that produced the major WS episode. This minor episode was associated with relatively low solar irradiation (i.e., increased cloudiness) 1-2 d before rainfall (Fig. 2B). Also clearly associated with the 1996 and 1997 episodes was a substantial increase in relative humidity shortly before, during, and after the WS-inducing rainfall. This was quantified in 1997 (Fig. 3) with the major episode of WS occurring during the predawn hours the day after a substantial rainstorm. A low level of splitting also occurred the day before the split-inducing rainfall (a very light rain occurred in the afternoon after WS occurred in the early morning hours). Thus, a low percentage of WS occurred $\approx 1 \mathrm{~d}$ before the major WS episode. Splitting always occurred during the predawn hours and was never observed after about 8:00 AM. This was also true for the occasional protrusion of a turgid seed coat through the split shell and shuck; such fruit did not split until the following night.

\section{Discussion}

These data confirm the observation by Worley and Taylor (1972), and the commonly held assumptions by growers, that rainfall during the early stages of shell hardening causes pecan fruit to split. More importantly, these data also indicate that rainfall per se is not the only causal factor, in that a minor WS episode can precede split-inducing rainfall. This was observed in both 1996 and 1997. While water from rainfall triggers the major WS episode, other factors clearly trigger the minor episode and factors also appear to contribute to the severity of the major episode.

The association of the minor episode with relatively low solar irradiance, high relative humidity, and absence of rainfall indicates that a rather sudden reduction in loss of water vapor by the tree's canopy during the WS susceptibility window contributes to WS. Failure of either major or minor WS episodes to develop in 1995, a season without substantial rainfall during the susceptibility window, indicates that WS is neither inevitable nor independent of weather conditions. Observations that lower solar irradiation and relative humidity often reduce water loss by foliage supports this possibility (Knapp, 1992; Meyer et al., 1973;). The observation that WS increased when an antitranspirant was applied just prior to a split-inducing rainfall also supports this possibility. These observations raise the possibility that such conditions suddenly increase water availability to developing fruit, resulting in a turgor pressure exceeding the containment capacity of the developing shell. Thus, besides rainfall, variation in the relative severity of WS losses with year, location, and trees within an orchard appears to be partially due to factors that influence evapotranspiration, such as cloud cover and relative humidity.

Cropping characteristics (such as fruit per cluster, crop load per tree, and location of the crop within the canopy) and soil moisture conditions prior to WS-inducing weather also contribute to the erratic nature of WS. The observed reduction (about one-third of the

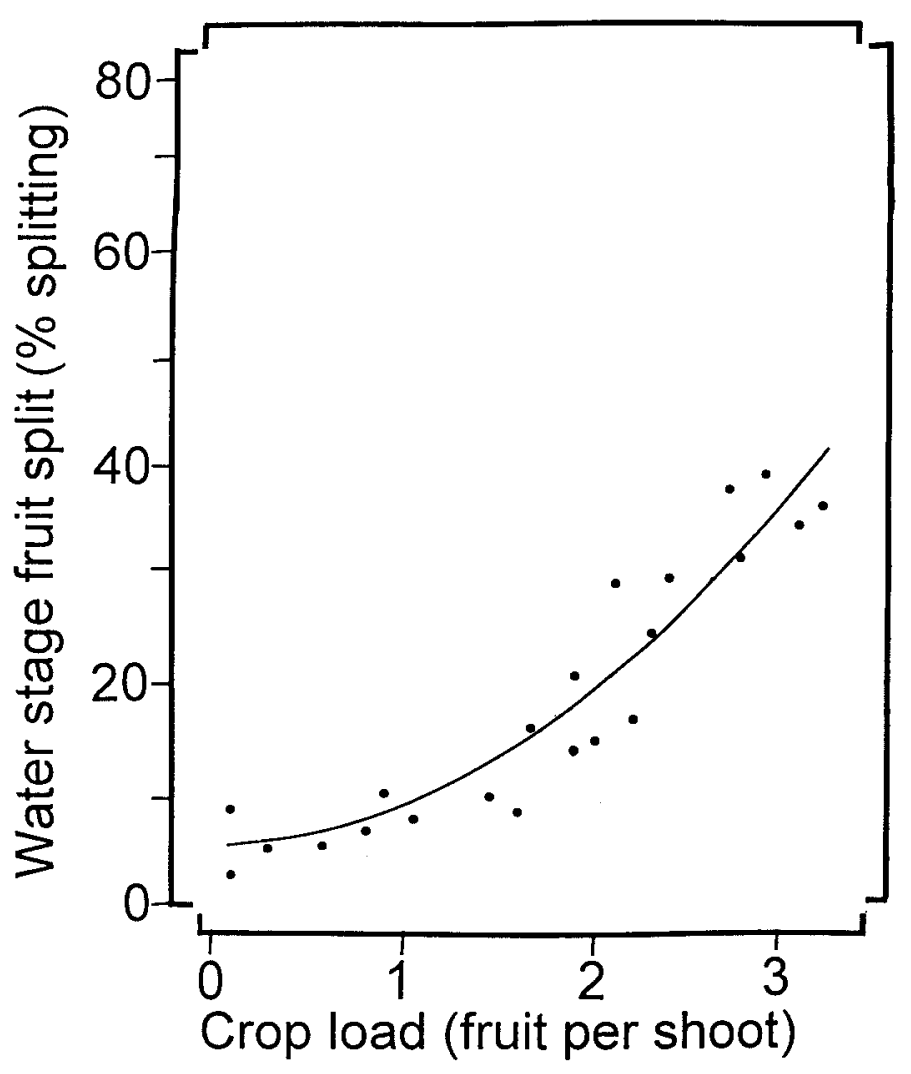

Fig. 1. Relationship between percentage of 'Wichita' pecan fruit exhibiting water stage split $(y)$ vs. crop load [(i.e., average number of fruit per shoot $(x)$ ]. The percentage of fruit exhibiting split is described by $y=$ $a+b x^{2}$, where $a=4.93, b=3.12$, and $r^{2}=0.89$. 


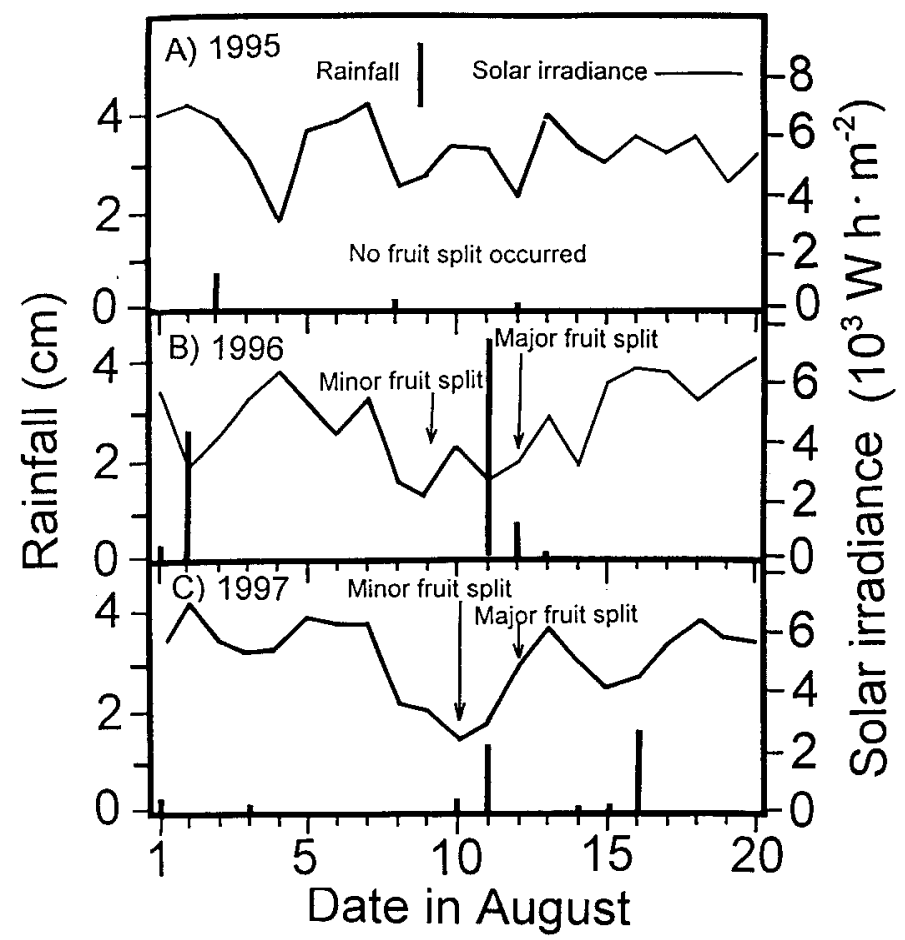

Fig. 2. Relationship between solar irradiance and rainfall vs. initiation of water stage fruit split of' 'Wichita' pecan fruit in a year when splitting did not occur (1995) and in years when it did (1996, 1997).

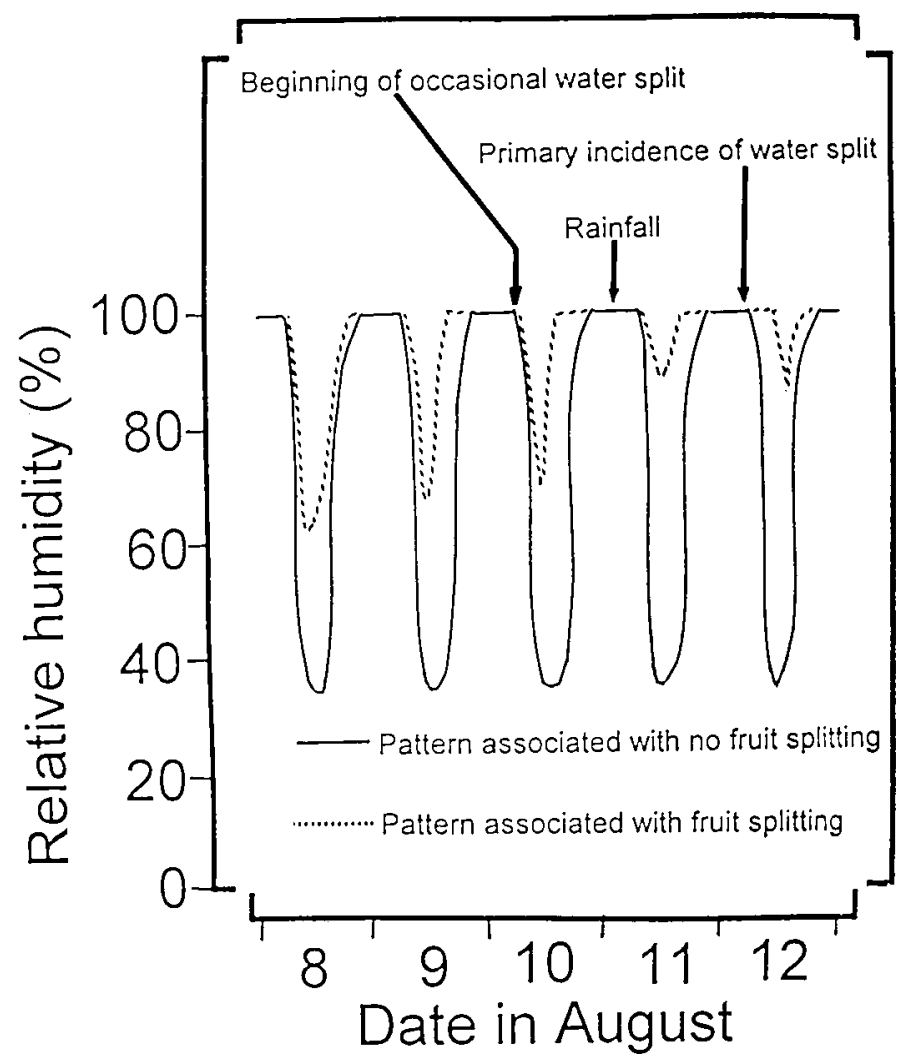

Fig. 3. Relationship between relative humidity and rainfall vs. the initiation of water stage fruit split of 'Wichita' pecan in 1997. The solid line is the relative humidity pattern typical of days just prior to splitinducing conditions and the dashed line is that observed when fruit splitting occurs.

nonirrigated control) in WS on trees exposed to relatively high levels of soil moisture for $\approx 2$ weeks prior to entering the WS susceptibility window, in comparison with those growing under relatively dry conditions, indicates that maintenance of soil moisture content prior to the beginning of shell hardening reduces WSrelated crop losses in certain years. While well-watered trees exhibited much less WS ( $8 \%$ to $12 \%$ ), maintenance of high soil moisture levels is unlikely to totally prevent WS. These data therefore indicate that withholding irrigation water until after the WS susceptibility stage has passed may actually enhance WS related crop losses in susceptible cultivars.

Water split can be a severe problem in certain cultivars in certain years. Under such conditions WS-related crop loss may be $\approx 70 \%$ to $90 \%$ (D. Sparks, personal communication). The incidence of WS observed in the present study was much less than that which occurs in some years. Because crop load and cluster size influence WS the difference in canopy position and cluster size observed here may not exist under conditions of heavy WS.

The increase in the severity of WS with increasing crop load indicates that crop thinning might reduce WS. Therefore mechanical thinning (Smith and Gallott, 1990) of the fruit crop prior to the initiation of shell hardening appears to offer potential for reducing losses. The combination of mechanical thinning with maintenance of high soil moisture prior to shell hardening therefore merits evaluation as a means to reduce the occurrence of WS.

These data support evidence presented by Allison et al. (1987) and Prussia et al. (1985) that WS is associated with an interaction between turgor pressure and shell strength. Findings from the present study, coupled with those by others (Allison et al., 1987; Prussia et al., 1985; Worley and Taylor, 1972; Storey, 1969) provide evidence that the fundamental solution to the WS problem can be found within the realms of water relations or shell hardening/timing characteristics (i.e., delaying rigidity development of shell tissue or substantially enhancing rigidity). Both approaches merit further study.

\section{Literature Cited}

Allison, J.M., S.E. Prussia, J.W. Daniell, and E.W. Tollner. 1987. Measuring the internal pressure of maturing pecans. Trans. Amer. Soc. Agr. Eng. 30:1869-1872.

Daniell, J.W. 1989. Irrigation, p. 73-85. In: W.D. Goff, J.R. McVay, and W.W. Gazaway (eds.). Pecan production in the southeast: A guide for growers. Alabama Coop. Ext. Serv., ANR-459.

Goode, J.E., M.M. Fuller, and K.J. Hyrycz. 1975. Skincracking of Cox's Orange Pippin apples in relation to water stress. J. Hort. Sci. 50:265-269.

Knapp, A.K. 1992. Leaf gas exchange in Quercus macrocarpa (Fagaceae): Rapid stomatal responses to variability in sunlight in a tree growth form. Amer. J. Bot. 89:599-604.

Meyer, B.S., D.B. Anderson, R.H. Bohning, and D.G. Fratianne. 1973. Introduction to plant physiology. D. Van Nostrand Co., New York.

Mrozek, R.F. and T.H. Burkhardt. 1973. Factors causing prune side cracking. Trans. Amer. Soc. Agr. Eng. 16:686-692, 695.

Prussia, S.A., D.T. Campbell, E.W. Tollner, and J.W. Daniell. 1985. Apparent modules of elasticity of maturing pecans. Trans. Amer. Soc. Agr. Eng. 28:1290-1296.

SAS Institute. 1990. SAS/Graph Software: Reference, version 6, vol. 2. SAS Inst., Cary, N.C.

Smith, M.W. and J.C. Gallott. 1990. Mechanical thinning of pecan fruit. HortScience 25:414-416.

Storey, J.B. 1969. Research notes. Pecan Quarterly $3: 20$.

Verner, L. and C.J. Blodgett. 1931. Physiological studies of the cracking of sweet cherries. Idaho Agr. Expt. Sta. Bul. 184:1-15.

Worley, R.E. and G.G. Taylor. 1972. An abnormal nut splitting problem of pecan (Carya illinoensis Koch). HortScience 7:70-71. 